\title{
Mechanocatalytic Production of Lactic Acid from Glucose by Ball Milling
}

\author{
Luyang Li ${ }^{1,2}$, Lulu Yan ${ }^{1}$, Feng Shen ${ }^{1}$, Mo Qiu ${ }^{1}$ and Xinhua Qi ${ }^{1, *}$ \\ 1 Agro-Environmental Protection Institute, Chinese Academy of Agricultural Sciences, No. 31, Fukang Road, \\ Nankai District, Tianjin 300191, China; sherlock_cool@126.com (L.L.); yanlulu2000@126.com (L.Y.); \\ shenwindy@126.com (F.S.); qiumo@aepi.org.cn (M.Q.) \\ 2 College of Environmental Science and Engineering, Nankai University, No. 94, Weijin Road, Nankai District, \\ Tianjin 300071, China \\ * Correspondence: qixinhua@nankai.edu.cn; Tel.: +86-22-2361-6651
}

Academic Editor: Christophe Len

Received: 13 April 2017; Accepted: 23 May 2017; Published: 1 June 2017

\begin{abstract}
A solvent-free process was developed for the direct production of lactic acid from glucose in a mechanocatalytic process in the presence of $\mathrm{Ba}(\mathrm{OH})_{2}$, and a moderate lactic acid yield of $35.6 \%$ was obtained. Glucose conversion and lactic acid formation were favorable at higher catalyst/glucose mass ratios. However, at relatively lower catalyst/glucose mass ratios, they were greatly inhibited, and the promotion of fructose formation was observed. The mechanocatalytic process was applicable for various carbohydrates such as $C_{5}$ sugars, $C_{6}$ sugars, and disaccharides with 20-36\% lactic acid yields achieved. This work provides a new pathway for the production of value-added chemicals from biomass resources.
\end{abstract}

Keywords: biomass; mechanochemical; glucose; lactic acid; ball milling; $\mathrm{Ba}(\mathrm{OH})_{2}$

\section{Introduction}

New and sustainable approaches to convert biomass resources to chemicals and fuels are required to address the concern of energy crisis and environmental pollution [1,2]. Many value-added chemicals such as formic acid, acetic acid, furfural, 5-hydroxymethylfurfural, and levulinic acid have been successfully synthesized from biomass starting materials such as monosaccharides (glucose and fructose), polysaccharides (sucrose, starch, and cellulose), or even raw bio-waste such as corn stalks, rice straws, and shrimp shells [3-5]. Among these chemicals, lactic acid is an important building-block intermediate which has wide applications in food, cosmetic, pharmaceutical, and chemical industries as well as in biodegradable plastics [6].

The large demand of lactic acid has stimulated the improvement of synthesis methods such as fermentation and chemocatalysis [7]. Although presently more than $90 \%$ of commercial lactic acid is produced by fermentation, this method suffers from the drawbacks of high cost, low productivity, and long fermentation time [6]. The chemocatalytic production of lactic acid from biomass has attracted increasing attention in recent years. Research has been conducted for the catalytic conversion of biomass and its derived carbohydrates to lactic acid/alkyl lactate in water or organic solvent, with diverse homogeneous or heterogeneous catalysts such as metal salts, zeolite, sodium silicate, and alkali $[7,8]$. The use of alkali in aqueous solutions has been proved to be efficient in producing lactic acid from biomass with low to moderate yields of $10-55 \%$ under harsh conditions [9-12]. However, a few problems still hinder the utilization of this method. The corrosion, energy consumption, and waste streams of the solvents also hamper the sustainable aspect of the catalytic conversion of biomass.

The mechanochemical process is an ancient synthesis method which normally refers to the solid-solid reaction induced by mechanical energy such as stretching, shearing, and grinding. Recent 
decades have witnessed a flourishing revival of mechanochemistry for its high efficiency, wide applications, and advantage regarding the concern of environmentally friendly and sustainable development [13]. Among its various applications, the mechanocatalysis of biomass has gained much attention because of its potential to be a green and practical pathway in biomass pretreatment. Lignocellulose can be more efficiently converted into sugars, alcohols, furfurals, and other biomass-derived chemicals after being pretreated by mechanochemical processes $[14,15]$. Cellulose and lignin were ball milled after being mixed with acidic and basic solid catalysts, respectively, and it was found that the mechanocatalysis process could depolymerize the substrates and result in water-soluble fractions, since the $\beta-1,4$ glyosidic bond and $\beta-\mathrm{O}-4$ linkage can be cleaved by a synergistic effect between the solid catalyst and mechanical forces [16-18]. Recent work has mainly focused on the mechanochemical pretreatment of lignocellulosic biomass, which could greatly increase the yield of target products or relieve the severity of reaction conditions followed by a tandem process of hydrothermal acid hydrolysis or enzymatic hydrolysis $[19,20]$.

In this work, an attempt was carried out to use glucose as a feedstock and a solid base, $\mathrm{Ba}(\mathrm{OH})_{2}$, as a catalyst in a ball milling process. It was found that moderate lactic acid yields could be achieved with the ball milling method. Although the yield was not as high as that reported in our previous work [21], it took a much shorter reaction time ( $4 \mathrm{~h}$ versus $48 \mathrm{~h}$ ), which should partly ascribed to the increase in the reaction temperature from 25 to $40{ }^{\circ} \mathrm{C}$. To our knowledge, this is the first report of the direct production of lactic acid from a biomass-derived substrate with the mechanocatalytic process, which provides a new method for the production of value-added chemicals from biomass resources.

\section{Results and Discussion}

\subsection{Effect of Milling Duration}

The catalytic conversion of glucose in the presence of a solid base, $\mathrm{Ba}(\mathrm{OH})_{2}$, in the ball milling process was examined. First, the effect of milling duration on glucose conversion was investigated (Figure 1). When the milling duration was shorter than $2 \mathrm{~h}$, the milling was operated continuously. When the milling duration was longer than $2 \mathrm{~h}$, milling was turned off every $2 \mathrm{~h}$ for $20 \mathrm{~min}$ to avoid overheating in the mill.

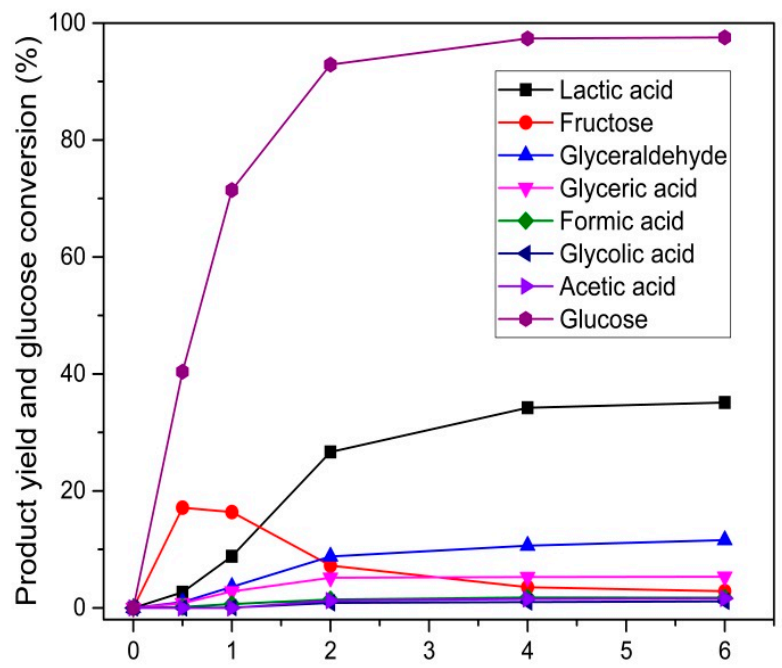

Figure 1. Glucose conversion and products distribution as a function of milling duration (Conditions: glucose $\left.0.5 \mathrm{~g}, \mathrm{Ba}(\mathrm{OH})_{2} \cdot 8 \mathrm{H}_{2} \mathrm{O} 1.5 \mathrm{~g}, 500 \mathrm{r} / \mathrm{min}\right)$.

It can be seen that glucose could be effectively converted in the ball milling process, and $71.5 \%$ conversion could be observed within $1 \mathrm{~h}$. After $4 \mathrm{~h}$, above $97 \%$ of the glucose was converted. At the initial stage of ball milling, fructose was the main product, which achieved a maximum yield of 
$17.5 \%$ at $0.5 \mathrm{~h}$ and then gradually decreased to $2.4 \%$ after $6 \mathrm{~h}$. Meanwhile, as the reaction proceeded, the formation of lactic acid could be observed, and the yield of lactic acid gradually increased to $35.6 \%$ after $6 \mathrm{~h}$ milling duration. The other minor products included glyceraldehyde, glyceric acid, glycolic acid, acetic acid, and formic acid, and they were generally formed in the catalytic conversion of glucose by base catalysts under hydrothermal conditions $[9,10]$. These results indicated that glucose could be effectively converted into lactic acid by mechanocatalysis in the presence of $\mathrm{Ba}(\mathrm{OH})_{2}$. From the products distribution shown in Figure 1, it is assumed that glucose is first isomerized to fructose by $\mathrm{Ba}(\mathrm{OH})_{2}$, followed by retro-aldol fragmentation into glyceraldehyde and dihydroxyacetone. Glyceraldehyde is one of the main intermediates in the catalytic conversion of $C^{6}$ sugars under hydrothermal conditions [22] and had a yield of $11.6 \%$ after $6 \mathrm{~h}$ milling duration in this work. It should be noted that dihydroxyacetone and pyruvaldehyde were not detected, which probably resulted from their instantaneous conversion to lactic acid and other byproducts once generated in the reaction system [11]. The other small molecular organic acids originated from the further oxidative cleavage of glyceraldehyde and dihydroxyacetone. In the control experiment for the ball milling treatment of glucose without addition of $\mathrm{Ba}(\mathrm{OH})_{2}$, no glucose conversion was observed. Also, a simple mixture of solid $\mathrm{Ba}(\mathrm{OH})_{2}$ and glucose maintained for $48 \mathrm{~h}$ led to no change in the feedstock. These phenomena indicated the synergistic effect of the mechanochemical and base catalyst.

\subsection{Effect of Sample/Ball Mass Ratio}

In the mechanocatalytic reaction, the sample/ball mass ratio may have some effect on the ball milling process, and an appropriate sample/ball mass ratio benefits the reaction because of the sufficient movement and contact among balls, substrates, and the mill jar wall. The energy produced from rub, compression, and impact induces the chemical reaction and synergic effect between the catalyst and substrate, and contributes to the formation of products [23]. A series of sample/ball mass ratios were studied to examine its influence on the ball milling process. Ten $\mathrm{ZrO}_{2}$ balls were used (ca. $20 \mathrm{~g}$ ) and different sample masses consisting of $\mathrm{Ba}(\mathrm{OH})_{2}$ and glucose with a mass ratio of 3:1 (total mass $1 \mathrm{~g}, 2 \mathrm{~g}$, and $4 \mathrm{~g}$ ) were ground for $4 \mathrm{~h}$ (Figure 2a). Similarly, the effect of variation of the number of balls was also investigated by fixing the substrate amount $(2 \mathrm{~g})$, but changing the number of balls (Figure $2 b$ ). It seems that there was no remarkable variation in glucose conversion, products distribution, or yield, either by changing the total sample mass or the ball number. In all cases, the yields of lactic acid and glyceraldehyde were around $34 \%$ and $9 \%$, respectively, and the other products including fructose, glyceric acid, glycolic acid, acetic acid, and formic acid had yields ranging from $1 \%$ to $6 \%$.
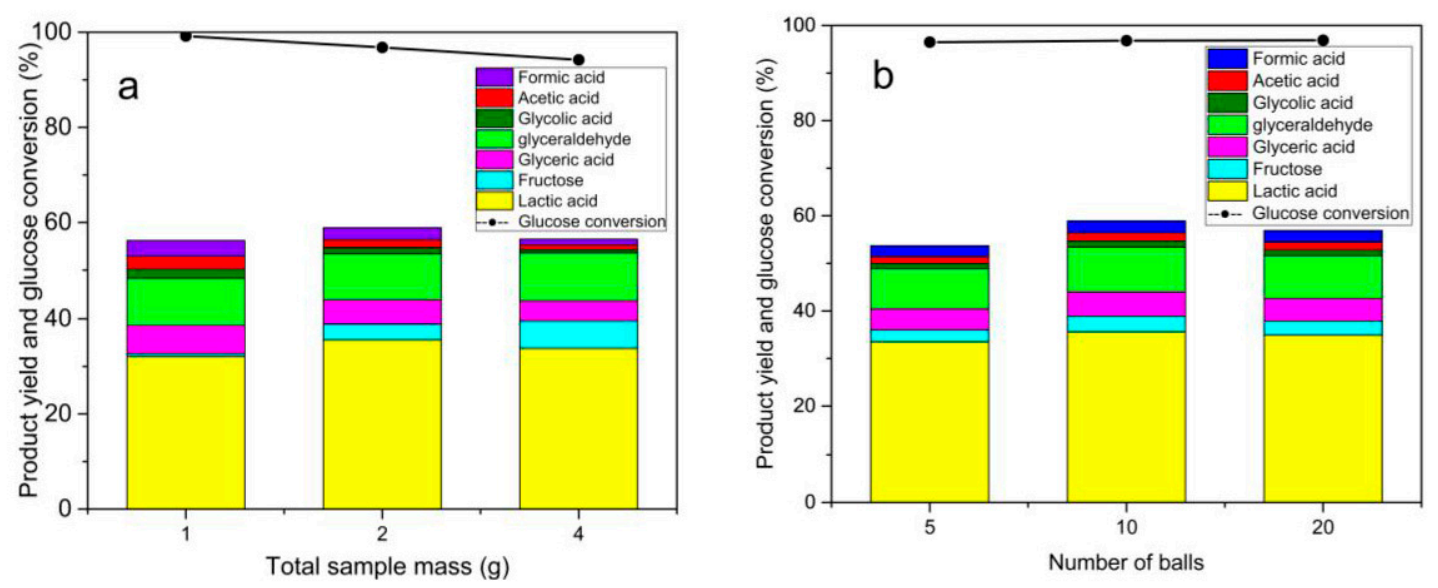

Figure 2. Effect of different sample/ball mass ratios on the products distribution in the mechanochemical process: (a) Fixed ball number (10) but changed total sample mass; (b) Fixed total sample mass ( $2 \mathrm{~g}$ ) but changed ball number (Conditions: $500 \mathrm{r} / \mathrm{min}, 4 \mathrm{~h}$ ). 


\subsection{Effect of Base/Glucose Mass Ratio}

The effect of the base/glucose mass ratio on the glucose conversion in the mechanocatalytic process was investigated, where the total sample mass was fixed as $2 \mathrm{~g}$. $\mathrm{Ten} \mathrm{ZrO}_{2}$ balls were used and the ball milling duration was $4 \mathrm{~h}$. The results are depicted in Figure 3, which shows that the base/glucose mass ratio had a great influence on both the glucose conversion, lactic acid yield, and the products distribution. Under high base/glucose mass ratio conditions (9:1 and 3:1), glucose could be effectively converted with a conversion higher than $96.5 \%$ and lactic acid was the main product (around $34 \%$ yield). When more glucose was used and the base/glucose mass ratio decreased to 1:1 and 1:3, the glucose conversion decreased sharply to $63.1 \%$ and $24.9 \%$, respectively. Meanwhile, the formation of lactic acid was nearly inhibited and fructose became the main product by the isomerization of glucose. Therefore, in the mechanocatalytic process of glucose, a higher base/glucose mass ratio favors the conversion of glucose and lactic acid formation, and a relatively low base/glucose mass ratio is unfavorable for the conversion of glucose and lactic acid production, but beneficial for the fructose formation.

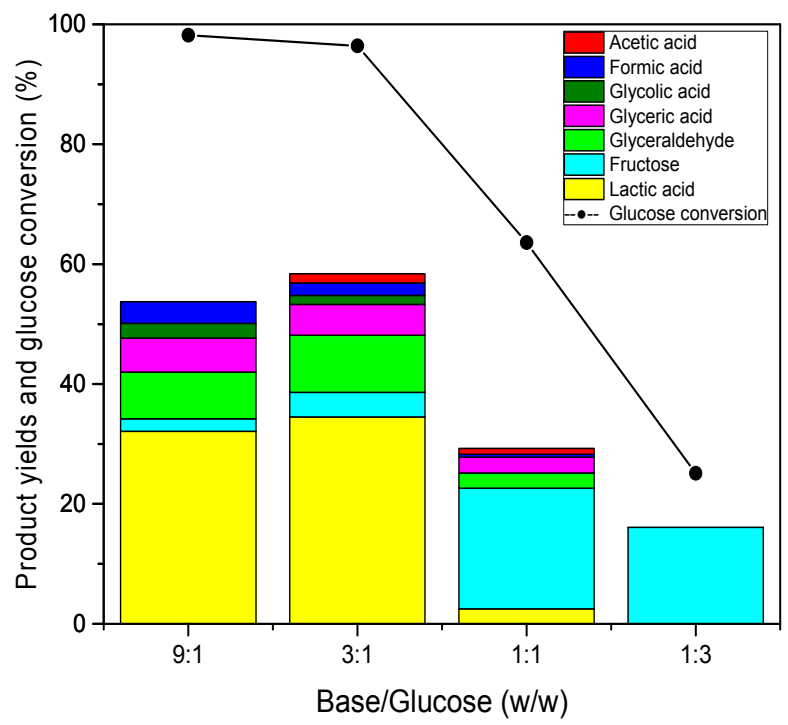

Figure 3. Effect of the base/glucose mass ratio on the glucose conversion in the mechanocatalytic process (Condition: $2 \mathrm{~g}$ total sample mass, 10 balls, $4 \mathrm{~h}$ ).

\subsection{Mechanocatalytic Conversion of Different Carbohydrates to Lactic Acid}

Various carbohydrates, including $\mathrm{C}_{5}$ and $\mathrm{C}_{6}$ monosaccharides and disaccharides, were used as feedstocks for the mechanocatalytic production of lactic acid in the presence of $\mathrm{Ba}(\mathrm{OH})_{2}$. As shown in Figure 4 , all of these carbohydrates were efficiently converted with high conversion over $96 \%$, and lactic acid could be effectively generated as the main product from these feedstocks. It is interesting that C5 monosaccharides such as xylose and arabinose could also lead to more than $30 \%$ lactic acid yields, the detailed mechanism of which will be investigated in future work. In addition, disaccharides such as cellobiose and lactose could be converted into lactic acid with around $20 \%$ yield. Prolonging the reaction time for disaccharides to $8 \mathrm{~h}$ did not increase lactic acid yield too much, and only a $\sim 4 \%$ increment in lactic acid yield was observed. The lower lactic acid yield from disaccharides compared to monosaccharides can be attributed to the fact that it was subjected to an additional hydrolysis step before the lactic acid formation from glucose. Based on these results, mechanocatalysis was shown to be an efficient method for the production of lactic acid with moderate yields from various carbohydrates. 


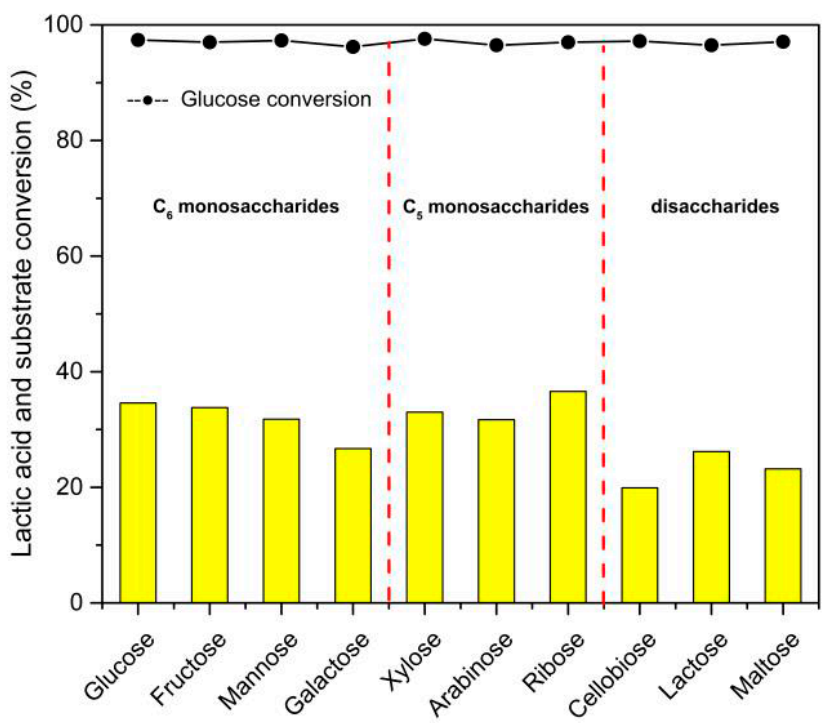

Figure 4. Conversion of different carbohydrates (Condition: $1.5 \mathrm{~g} \mathrm{Ba}(\mathrm{OH})_{2} \cdot 8 \mathrm{H}_{2} \mathrm{O}, 0.5 \mathrm{~g}$ carbohydrate, $500 \mathrm{r} / \mathrm{min}, 4 \mathrm{~h})$.

For comparison, the lactic acid production from glucose and fructose by mechanocatalysis in this work and those by the other conventional chemocatalytic processes in the references are listed in Table 1. It can be seen that, from the aspect of lactic acid yield, the mechanocatalytic process in this work is comparable to some of the chemocatalytic processes. More importantly, this work provides a new strategy for the production of value-added chemicals from biomass resources. To further improve the lactic acid yield in the mechanochemical process, more efforts on catalyst development and process intensification have to be made in future work.

Table 1. Comparison of the production of lactic acid between mechanocatalytic and chemocatalytic processes.

\begin{tabular}{|c|c|c|c|c|c|c|c|}
\hline Substrate & Catalyst & Condition & Solvent & $\begin{array}{c}\text { Substrate } \\
\text { Concentration } \\
\text { (M) }\end{array}$ & $\begin{array}{c}\text { Substrat } \\
\text { Conversion } \\
(\%)\end{array}$ & $\begin{array}{c}\text { Lactic } \\
\text { Acid/Methyl } \\
\text { Lactate Yield } \\
\text { (mol \%) }\end{array}$ & Reference \\
\hline Glucose & $\begin{array}{c}\mathrm{Ba}(\mathrm{OH})_{2} \\
\text { Solid 1.5 g }\end{array}$ & $\begin{array}{l}500 \mathrm{r} / \mathrm{min} \\
4 \mathrm{~h}, \sim 40^{\circ} \mathrm{C}\end{array}$ & none & $0.5 \mathrm{~g}$ & 98.1 & 35.6 & This work \\
\hline Fructose & $\begin{array}{c}\mathrm{Ba}(\mathrm{OH})_{2} \\
\text { Solid } 1.5 \mathrm{~g}\end{array}$ & $\begin{array}{l}500 \mathrm{r} / \mathrm{min} \\
4 \mathrm{~h}, \sim 40^{\circ} \mathrm{C}\end{array}$ & none & $0.5 \mathrm{~g}$ & 97.7 & 35.1 & This work \\
\hline Glucose & $\mathrm{Ba}(\mathrm{OH})_{2}$ & $25^{\circ} \mathrm{C}, 48 \mathrm{~h}$ & Water & 0.1 & 97.4 & 78.3 & [21] \\
\hline Fructose & $\mathrm{Ba}(\mathrm{OH})_{2}$ & $25^{\circ} \mathrm{C}, 48 \mathrm{~h}$ & Water & 0.1 & 98.7 & 83.5 & [21] \\
\hline Glucose & $\mathrm{LaCoO}_{3}$ & $200^{\circ} \mathrm{C}, 1 \mathrm{~h}$ & Water & 0.05 & $\mathrm{~N} / \mathrm{A}$ & 39.5 & [24] \\
\hline Glucose & $\mathrm{InCl}_{3} \cdot 4 \mathrm{H}_{2} \mathrm{O}$ & $200^{\circ} \mathrm{C}, 10 \mathrm{~h}$ & Methanol & 0.0025 & 97 & 52 & [25] \\
\hline Glucose & $\begin{array}{l}\text { Sn-MCM-41 } \\
(\mathrm{Si} / \mathrm{Sn}=55)\end{array}$ & $160^{\circ} \mathrm{C}, 20 \mathrm{~h}$ & Methanol & 0.125 & 100 & 43 & [26] \\
\hline Glucose & $\mathrm{Na}_{2} \mathrm{SiO}_{3}$ & $300^{\circ} \mathrm{C}, 1 \mathrm{~min}$ & Water & 0.1 & $\mathrm{~N} / \mathrm{A}$ & 30 & [27] \\
\hline Glucose & $\mathrm{NaOH}-\mathrm{NiCl}_{2}$ & $300^{\circ} \mathrm{C}, 1 \mathrm{~min}$ & Water & 0.097 & $\mathrm{~N} / \mathrm{A}$ & 25 & [28] \\
\hline Fructose & Zr-SBA-15 & $240^{\circ} \mathrm{C}, 6 \mathrm{~h}$ & Methanol & 0.056 & $\mathrm{~N} / \mathrm{A}$ & 44.1 & [29] \\
\hline Fructose & Ti-Beta & $160^{\circ} \mathrm{C}, 20 \mathrm{~h}$ & Methanol & 0.125 & 99 & 36 & [30] \\
\hline Fructose & Sn-Beta & $160^{\circ} \mathrm{C}, 16 \mathrm{~h}$ & Methanol & 0.125 & 98 & 54 & [31] \\
\hline Fructose & $\left(\mathrm{C}_{4} \mathrm{H}_{9}\right)_{2} \mathrm{SnO}$ & $190^{\circ} \mathrm{C}, 0.5 \mathrm{~h}$ & Water & 0.044 & $\mathrm{~N} / \mathrm{A}$ & 63 & [32] \\
\hline
\end{tabular}

\section{Materials and Methods}

\subsection{Materials}

Glucose (99\%), fructose (99\%), and xylose (98\%) were purchased from Aladding Industrial Corporation (Shanghai, China). Mannose (99\%), galactose (99\%), lactose (98\%), cellbiose ( $98 \%)$, ribose (99\%), and $\mathrm{Ba}(\mathrm{OH})_{2} \cdot 8 \mathrm{H}_{2} \mathrm{O}(98 \%)$ were obtained from J\&K Scientific Ltd., (Beijing, China). Arabinose (99\%) was provided by Solarbio Agent Company (Beijing, China). Lactic acid (98\%), formic acid (98\%), 
glycolic acid (98\%), and glyceraldehyde (98\%) were bought from Sinophram Company (Beijing, China). Sulfuric acid aqueous solution (0.5 M) was purchased from Macklin Biochemical Company (Shanghai, China) . All chemicals were used without further purification.

\subsection{Mechanocatalytic Process}

The mechanocatalytic experiments were conducted with a planetary ball mill (DECO-PBM-V-21, Changsha DECO equipment Co. Ltd. (Changsha, Hunan, China). Typically, a 2-g mixture of substrate and catalyst was loaded into a 50-mL PolyTetraFluoroEthylene (PTFE) mill jar with $10 \mathrm{ZrO}_{2}$ balls which each had diameter of $1 \mathrm{~cm}$ and an approximate weight of $2 \mathrm{~g}$. The mass ratio of sample/ball was 1:10 for all the experiments, and various base/glucose ratios were studied. The shaking rate was set to $500 \mathrm{r} / \mathrm{min}$ and the ball mill was paused for 20 min every $2 \mathrm{~h}$ of continuous milling in order to dissipate the possible heat produced. The temperature inside the mill jar was not over $40^{\circ} \mathrm{C}$.

\subsection{Products Analysis}

After the ball milling process, $20 \mathrm{~mL} 0.5 \mathrm{M} \mathrm{H}_{2} \mathrm{SO}_{4}$ was purged into the mill jar to neutralize the base and acidize the possible salt products to their corresponding free acids. The mixture was stirred thoroughly to dissolve the products, and then centrifuged to obtain a clear solution. HPLC (Waters Acquity UPLC H-Class, Milford, MA, USA) was used to analyze the products. RI and UV detectors were connected in series in the system and were equipped with a Shodex SUGAR SH1011 column (SHOWA DENKO K.K., Tokyo, Japan). The temperature of the RI detector and column was set to 35 and $50{ }^{\circ} \mathrm{C}$, respectively. A wavelength of $210 \mathrm{~nm}$ was used for the UV detector. $5 \mathrm{mM}$ dilute sulfuric acid aqueous solution was used as the mobile phase at a flow rate of $0.5 \mathrm{~mL} / \mathrm{min}$.

All experiments were replicated at least three times, and the results were the mean values of the repeated trials and had relative deviations below $5 \%$. The main values for the substrate conversion and products yield were calculated on carbon basis as follows:

$$
\begin{gathered}
\text { Substrate conversion }(\%)=\left\{1-\left(\frac{\text { molar concentration of remaining substrate }}{\text { molar concentration of feed substrate }}\right) \times 100 \%\right\} \\
\text { Product yield }(\%)=\left\{\left(\frac{\text { moles of carbon in the product }}{\text { moles of carbon in the feed substrate }}\right) \times 100 \%\right\}
\end{gathered}
$$

\section{Conclusions}

In this work, lactic acid was directly produced from glucose by ball milling in the presence of $\mathrm{Ba}(\mathrm{OH})_{2}$ as a base catalyst, and the highest lactic acid yield of $35.6 \%$ was achieved after $6 \mathrm{~h}$ milling duration. In the ball milling process, a higher base/glucose mass ratio favored glucose conversion and the formation of lactic acid, while a relatively low base/glucose mass ratio was unfavorable for glucose conversion and lactic acid production, but beneficial for fructose formation. The proposed ball milling process is also applicable for the conversion of various carbohydrates with a lactic acid yield ranging from $20 \%$ to $36 \%$.

Acknowledgments: The authors greatly thank the financial support from NSFC (No. 21577073), the Natural Science Foundation of Tianjin (No. 16JCZDJC33700) and Elite Youth program of Chinese Academy of Agricultural Sciences (to Xinhua Qi).

Author Contributions: L.L. and X.Q. conceived and designed the experiments; L.L. and Y.L. performed the experiments; F.S. and M.Q. analyzed the data, L.L. and X.Q. wrote the paper.

Conflicts of Interest: The authors declare no conflict of interest. 


\section{References}

1. Barta, K.; Ford, P.C. Catalytic Conversion of Nonfood Woody Biomass Solids to Organic Liquids. Acc. Chem. Res. 2014, 47, 1503-1512. [CrossRef] [PubMed]

2. Vávrová, K.; Knápek, J.; Weger, J. Short-term Boosting of Biomass Energy Sources-Determination of Biomass Potential for Prevention of Regional Crisis Situations. Renew. Sustain. Energy Rev. 2017, 67, 426-436. [CrossRef]

3. Qi, L.; Mui, Y.F.; Lo, S.W.; Lui, M.Y.; Akien, G.R.; Horváth, I.T. Catalytic Conversion of Fructose, Glucose, and Sucrose to 5-(Hydroxymethyl)furfural and Levulinic and Formic Acids in $\gamma$-Valerolactone As a Green Solvent. ACS Catal. 2014, 4, 1470-1477. [CrossRef]

4. Yan, L.; Liu, N.; Yu, W.; Machida, H.; Qi, X. Production of 5-Hydroxymethylfurfural from Corn Stalk Catalyzed by Corn Stalk-derived Carbonaceous Solid Acid Catalyst. Bioresour. Technol. 2014, 173, 462-466. [CrossRef] [PubMed]

5. Gao, X.; Chen, X.; Zhang, J.; Guo, W.; Jin, F.; Yan, N. Transformation of Chitin and Waste Shrimp Shells into Acetic Acid and Pyrrole. ACS Sustain. Chem. Eng. 2016, 4, 3912-3920. [CrossRef]

6. Mäkiarvela, P.; Simakova, I.L.; Salmi, T.; Murzin, D.Y. Production of Lactic Acid/Lactates from Biomass and Their Catalytic Transformations to Commodities. Chem. Rev. 2014, 114, 1909-1971. [CrossRef] [PubMed]

7. Dusselier, M.; Wouwe, P.V.; Dewaele, A.; Makshina, E.; Sels, B.F. Lactic Acid as a Platform Chemical in the Biobased Economy: The Role of Chemocatalysis. Energy Environ. Sci. 2013, 6, 1415-1442. [CrossRef]

8. Morales, M. Environmental and Economic Assessment of Lactic Acid Production from Glycerol using Cascade Bio- and Chemocatalysis. Energy Environ. Sci. 2015, 8, 558-567. [CrossRef]

9. Yan, L.; Qi, X. Degradation of Cellulose to Organic Acids in its Homogeneous Alkaline Aqueous Solution. ACS Sustain. Chem. Eng. 2014, 2, 897-901. [CrossRef]

10. Esposito, D. Chemical Conversion of Sugars to Lactic Acid by Alkaline Hydrothermal Processes. ChemSusChem 2013, 6, 989-992. [CrossRef] [PubMed]

11. Lux, S.; Siebenhofer, M. Synthesis of Lactic Acid from Dihydroxyacetone: Use of Alkaline-earth Metal Hydroxides. Catal. Sci. Technol. 2013, 3, 1380-1385. [CrossRef]

12. Shen, Z.; Jin, F.; Zhang, Y.; Wu, B.; Kishita, A.; Tohji, K.; Kishida, H. Effect of Alkaline Catalysts on Hydrothermal Conversion of Glycerin into Lactic Acid. AIChE J. 2009, 56, 2727-2733. [CrossRef]

13. James, S.L.; Adams, C.J.; Bolm, C.; Braga, D.; Collier, P.; Friscic, T.; Grepioni, F.; Harris, K.D.M.; Hyett, G.; Jones, W.; et al. Mechanochemistry: Opportunities for New and Cleaner Synthesis. Chem. Soc. Rev. 2012, 41, 413-447. [CrossRef] [PubMed]

14. Carrasquilloflores, R.; Käldström, M.; Schüth, F.; Dumesic, J.A.; Rinaldi, R. Mechanocatalytic Depolymerization of Dry (Ligno)cellulose As an Entry Process for High-Yield Production of Furfurals. ACS Catal. 2013, 3, 11167-11173.

15. Hilgert, J.; Meine, N.; Rinaldi, R.; Schüth, F. Mechanocatalytic Depolymerization of Cellulose Combined with Hydrogenolysis as a Highly Efficient Pathway to Sugar Alcohols. Energy Environ. Sci. 2013, 6, 92-96. [CrossRef]

16. Hick, S.M.; Griebel, C.; Restrepo, D.T.; Truitt, J.H.; Buker, E.J.; Bylda, C.; Blair, R.G. Mechanocatalysis for Biomass-derived Chemicals and Fuels. Green Chem. 2010, 12, 468-474. [CrossRef]

17. Käldström, M. Deciphering 'Water-soluble Lignocellulose' Obtained by Mechanocatalysis: New Insights into the Chemical Processes Leading to Deep Depolymerization. Green Chem. 2014, 16, 3528-3538. [CrossRef]

18. Kleine, T.; Buendia, J.; Bolm, C. Mechanochemical Degradation of Lignin and Wood by Solvent-free Grinding in a Reactive Medium. Green Chem. 2012, 15, 160-166. [CrossRef]

19. Schneider, L.; Haverinen, J.; Jaakkola, M.; Lassi, U. Solid Acid-catalyzed Depolymerization of Barley Straw Driven by Ball Milling. Bioresour. Technol. 2016, 206, 204-210. [CrossRef] [PubMed]

20. Loustaucazalet, C.; Sambusiti, C.; Buche, P.; Solhy, A.; Bilal, E.; Larzek, M.; Barakat, A. Innovative Deconstruction of Biomass Induced by Dry Chemo-Mechanical Activation: Impact on Enzymatic Hydrolysis and Energy Efficiency. ACS Sustain. Chem. Eng. 2016, 4, 2689-2697. [CrossRef]

21. Li, L.; Shen, F.; Smith, R.L.; Qi, X. Quantitative Chemocatalytic Production of Lactic Acid from Glucose under Anaerobic Conditions at Room Temperature. Green Chem. 2017, 19, 76-81. [CrossRef] 
22. Tang, Z.; Deng, W.; Wang, Y.; Zhu, E.; Wan, X.; Zhang, Q.; Wang, Y. Transformation of Cellulose and its Derived Carbohydrates into Formic and Lactic Acids Catalyzed by Vanadyl Cations. ChemSusChem 2014, 7, 1557-1567. [CrossRef] [PubMed]

23. Gorrasi, G.; Sorrentino, A. Mechanical Milling as a Technology to Produce Dtructural and Functional Bio-nanocomposites. Green Chem. 2015, 17, 2610-2625. [CrossRef]

24. Yang, X.; Yang, L.; Fan, W.; Lin, H. Effect of Redox Properties of $\mathrm{LaCoO}_{3}$ Perovskite Catalyst on Production of Lactic Acid From Cellulosic Biomass. Catal. Today 2016, 269, 56-64. [CrossRef]

25. Nemoto, K.; Hirano, Y.; Hirata, K.I.; Takahashi, T.; Tsuneki, H.; Tominaga, K.I.; Sato, K. Cooperative In-Sn Catalyst System for Efficient Methyl Lactate Synthesis from Biomass-derived Sugars. Appl. Catal. B Environ. 2016, 183, 8-17. [CrossRef]

26. Murillo, B. Conversion of Glucose to Lactic Acid Derivatives with Mesoporous Sn-MCM-41 and Microporous Titanosilicates. J. Chem. Technol. Biotechnol. 2014, 89, 1344-1350. [CrossRef]

27. Jia, D.; Zhang, Z.; Yao, G.; Huo, Z.; Jin, F. Hydrothermal Conversion of Glucose into Lactic Acid with Sodium Silicate as a Base Catalyst. Catal. Today 2016, 263, 112-116.

28. Huo, Z.; Fang, Y.; Ren, D.; Zhang, S.; Yao, G.; Zeng, X.; Jin, F. Selective Conversion of Glucose into Lactic Acid with Transition Metal Ions in Diluted Aqueous NaOH Solution. ACS Sustain. Chem. Eng. 2014, 2, 2765-2771. [CrossRef]

29. Yang, L.; Yang, X.; Tian, E.; Vattipalli, V.; Fan, W.; Lin, H. Mechanistic Insights into the Production of Methyl Lactate by Catalytic Conversion of Carbohydrates on Mesoporous Zr-SBA-15. J. Catal. 2016, 333, 207-216. [CrossRef]

30. Holm, M.S.; Saravanamurugan, S.; Taarning, E. Conversion of Sugars to Lactic Acid Derivatives using Heterogeneous Zeotype Catalysts. Science 2010, 328, 602-605. [CrossRef] [PubMed]

31. Holm, M.S.; Pagántorres, Y.J.; Saravanamurugan, S.; Riisager, A.; Dumesic, J.A.; Taarning, E. Sn-Beta Catalysed Conversion of Hemicellulosic Sugars. Green Chem. 2012, 14, 702-706. [CrossRef]

32. Santos, J.B.D. Fructose Conversion in the Presence of Sn(IV) Catalysts Exhibiting High Selectivity to Lactic Acid. RSC Adv. 2015, 5, 90952-90959. [CrossRef] 